\title{
How Does Parental Involvement Affect Children's Academic Development from A Core Literacy Perspective?
}

\author{
Wenyan Liang, Ran Sun, Xiaomei Ye \\ Beijing Normal University, Beijing 100875, China
}

\begin{abstract}
This study explores the influence of parental involvement on children's academic development, and comprehensively defines the indicators of children's academic development from the perspective of core literacy. Based on urban and rural household registration status and regional migration, children in China are divided into four categories. Three main findings are as follows. First, parents' direct learning participation can hardly benefit children's academic development, regardless of what type of children. Specifically, this type of parental participation has a significant negative impact not only on academic test score of all children, but also on all academic development dimensions of children who have rural to urban migrant experience. Second, parents' emotional participation behavior can effectively promote the academic development of children, regardless of migration type. Third, parents' cultural participation has a positive effect on local urban children's academic development, while it has a negative effect on the learning willpower and curiosity of urban-urban migrant children who move from one urban area to another in different provinces/districts. Under the background of mass internal migration and rapid urbanization, our findings provide implications for parents to better participate in their children's education in the context of rapid population movements and urbanization.
\end{abstract}




\section{Research Background and Problem}

$\mathrm{E}$

XPLORING the impact of parental involvement on children's academic development is a key research issue, while helping parents improve their participation is regarded as a way to promote children's academic development (Fan \& Chen, 2001). For example, the United States has implemented some homeschool cooperative programs such as "Head Start"" and "Success for All", to help parents from disadvantaged groups to better participate in their children's learning (Currie, 1997; Hill \& Tyson, 2009). In China, some researchers have tried to explore the influence of parental involvement on children's academic development based on different samples from different regions or different educational stage. However, as China has experienced rapid internal rural-urban migration or regional migration, and almost all of public welfare such as education is depending on household registration, then further studies are required to explore the research question mentioned above.

On the one hand, most related studies only focus on children's test scores (Hill \& Tyson, 2009; Altschul, 2011; Jona et al., 2013; Wilder, 2014), while a single dimension of outcome would be no longer in line with the demand of future society. In fact, there will be full of uncertainty and challenges in the future, it requires that children' academic development should be comprehensive and diverse. As Heckman et al. (2006) pointed out that the disciplinary knowledge taught by schools in the era of information and globalization is depreciating at an accelerating rate; as a result children must not only acquire subject knowledge, but also acquire the literacy and skill of adapting to varied complex situations. That means if we overlook children's developments in areas which are not measured by subject test scores; we will not only hinder children's ability to have a high quality and happy life, but also affect the country's labor quality and social well-being. In the existing literature, only very limited number of scholars express concern regarding the effects of parents' participation on children's academic developments other than test score: self-educational expectations (Brooks et al., 1997; Gonzalez et al., 2002), learning effectiveness (Fan \& Williams, 2010), learning autonomy (Shao, et al., 2016), et al. However, these studies are mostly carried out by psychologists and not educators, measures of parental participation are decentralized and sporadic. Without a common framework, it is difficult to obtain a holistic conclusion through existing researches.

\footnotetext{
About the Author: Ran Sun, Anhui, Master's Student of the Department of Education, Beijing Normal University, Email: ransunsunny@163.com

Xiaomei Ye, Henan, Ph.D. Candidate, Department of Education, Beijing Normal University, Email: iikeer@163.com.

Correspondence to: Wenyan Liang, Ph.D., Associate Professor, Institute for Economics of Education, Faculty of Education, Beijing Normal University, Beijing 100875, China, Email: liangwenyan@bnu.edu.cn or wenyan_liang@163.com.

Funding: Major research projects of the Ministry of Education "'The research on the relationship between education and economic development and the contribution of them (15JZD040)", special fund for Disciplinary Construction in 2017 by the Department of Education of Beijing Normal University.
}

Conflict of Interests: None. 
On the other hand, among the previous related researches which focused on urban children's education development under the background of internal population migration, authors just focuses on RUMC (Zhou \& Wu, 2008; Shao, et al., 2016). In fact, according to population migration and existing hukou (Household Registration, in Chinese “户口”) segmentation policy, the urban resident children can be divided into four types: local urban children (LUC) without any migrant experience; ruralurban migrant children (RUMC) moving from rural to urban areas within the same province/district; urban-urban migrant children (UUMC) moving from one urban area to the other in different provinces/districts; and children who had moved from rural to urban areas in different provinces/districts with dual mobility experience (DMC). And ensuring each type of children gain better education is the basis for promoting social integration. Obviously, focusing only on DMC cannot explore the complete relationship between parental involvement and children's academic development in rapidly urbanizing China. Then it cannot provide specially and helpful suggestion for the improvement of parental involvement for different kinds of children.

Compared with the existing researches, this current study tried to gain improvements in the following two aspects. First, based on the framework of core literacy, we construct a more comprehensive indicator for the measurement of children' academic development. These indicators will cover both test-score and non-test score indicators. Second, according to hukou and regional mobility situation, we divide urban resident children into four types: LUC, RUMC, UUMC and DMC. Then, we explore and compare the relationship between parental involvement and children's academic achievement in such four children categories.

\section{Literature Review and Research Hypothesis}

\section{Indicator Framework for Children's Academic Development on the Framework of Core Literacy}

Children's academic development indicators can be mainly divided into two categories: 1) existing and directly available test performance indicators. These indicators can measure the academic achievement aspects of subject knowledge and other literacy skills; 2) specially designed and collected non-test score indicators. These indicators can measure the academic achievement aspects of learning abilities and attitudes (Chu, 2016). Studies regarding children's academic development have traditionally focused on the first category. Though it is important for children's education and social economic achievement (Hanushek \& Woessmann, 2008), it is insufficient to adapt the demand of the uncertain and challenging in future society (Chu, 2016). Although the second category indicators are often overlooked, they have benefits for children's long-term development and social well-being (Heckman et al., 2006).

What specific indicators should be included in assessment of a child's academic development? The "China Student Development Core Literacy" report, released in 2016, provides us a guided framework. Among the six aspects of core literacy pro- 
posed by the above report, the three aspects - cultural literacy, scientific spirit, and learning to learn-are closely related to academic development. Specifically, the aspect of cultural literacy emphasizes the basic ability of applying knowledge and skills; it includes indicators such as test scores and grades. The aspect of scientific spirit emphasizes value standards, thinking modes and behavioral expressions formed during the student's learning process; it includes indirect academic development indicators such as learning willpower and learning curiosity. The aspect of learning literacy emphasizes students' choice of learning methods, the performance of the learning process assessment and regulation; it includes indicators such as t self-learning ability, self-education expectations and other indirect academic development.

Among the existing literature, many scholars have studied children's academic development under the core literacy framework based on theoretical discussion (Yang, 2017) or international comparison (Chu, 2016). However, few scholars conduct empirical research based on the perspective of core literacy to assess the influence of parental involvement on children's academic development. This is the focus of current research.

\section{Parental Involvement on Children's Academic Development}

Referring to the study of Grolnick and Slowiaczek (1994), we divide parental involvement into three categories: direct learning participation, emotional participation, and cultural participation.

Firstly, direct learning participation (DLP) refers to parents directly intervening in the child's learning process, including checking homework, guiding homework, attending parent meeting, etc. In the existing literature, only a few studies conclude that parents' DPI significantly improves children's test scores (Li, 2017). Most studies have found that such parental participation behavior has no positive effect on children's academic test scores and can even have negative effects. (Sui-Chu \& Willms, 1996; Patall et al., 2008; Zhao \& Hong, 2012; Li \& Zheng, 2016). Nonetheless, some studies that use non-test scores as a result variable suggest that such participation has a positive effect, for example, to enhance children's learning willpower (Gonzalez et al., 2002; Fan \& Williams, 2010), learning adaptability (Plunkett et al., 2008) and self-educational expectations and learning autonomy (Gonzalez et al., 2002).

The second type of parental involvement is emotional participation (EP) that refers to parental communication with their children and corresponding responsiveness to their children' needs. Such participation includes parents communicating with their kids and discussing matters related to school and study. Research suggests that EP can improve children's academic test scores (Sui-Chu \& Willms, 1996; Zhao \& Hong, 2012), promote children's self-learning ability (He \& Li, 2000), learning willpower (Huang \& Huo, 2014), learning autonomy (Liu \& Teng, 2016) and other nontest scores.

Finally, cultural participation (CP) refers to parents guiding their children to participate in various cultural activities, including accompanying children to read, 
visiting museums, and watching cultural performances. Studies suggest that parental CP behavior not only helps improve children's academic test scores (Grolnick \& Slowiaczek, 1994; Altschul, 2012; Sibley \& Dearing, 2014), but also enhances children's interest in learning, their learning power, etc. (Brooks et al., 1997; Wang \& Sheikh-Khalil, 2014). However, cultural participation has higher requirements for parental literacy, and its positive impact is mainly observed in the upper middle class (Sibley \& Dearing, 2014).

Furthermore, after reviewing related literature, we found that the indicators chose by existing researches are scattered and not system. Each author only chose a few indicators in each paper, which restricts the comprehensiveness and comparability of research conclusions. In current research, we study the impact of the above three types of parental involvement on children's academic development under a unified analytical framework and outcome indicator framework. We propose the following three hypotheses:

H1: The more parents' DLP, the better their child's academic development would be.

H2: The more parents' EP, the better their child's academic development would be.

H3: The more parents' CP, the better their child's academic development would be.

\section{Migration, Hukou Segmentation, and Parental Involvement}

As mentioned above, Children living in cities are divided into LUC, RUMC, UUMC and DMC. Compared to children of the first category, the last three categories of children experience migration across of rural-urban or urban-urban or both. In a sense, RUMC, UUMC and DMC can be regarded as "outsiders" towards their current living city.

Due to the long-term existence of the urban-rural and regional divides in China, LUC, RUMC, UUMC and DMC differ in family socioeconomic status. First, parent of non-agricultural hukou, which are LUC and UUMC, have higher educational attainment, higher-level occupations and more stable jobs than the parent of other two types of children (Feng \& Chen, 2016: 67-70). Second, local parents, which are LUC and RUMC, are more familiar with the local labor market than other two types of non-local parents. Thus, local parents are more likely to have local social resources which lead to advantage in better job market (Xie, 2012). Third, as there exist different requirement for job skill among different regional labor market, then adult would face inescapable mismatch in inflow areas' labor market, so non-local parents' income level, job stability and flexibility would be affected (Xie, 2012). Presumably, we infer that, among such four types of children, their social and economic status of households sorting from highest to lowest would be: LUC, UUMC, RUMC and DMC.

Previous studies have shown that, parental involvement behavior is closely related to family socioeconomic level. First, among disadvantage families, lower economic income, longer and less flexible working hours, and higher unemployment risks would limit parent participate in their children's learning and life (Wu et al., 2017). Second, among disadvantage families, as parents have lower levels of 
knowledge and cultural literacy, which would limit them attach importance to their children education and have higher expectation for their children. As a result, these parents are more likely to lack planning in their children's educational involvement, especially ignore emotional participation and cultural participation (Altschul, 2012). In contrast, among advantage families, parents would have higher quality involvement. Owing to they own high-level learning experience, they can not only teach their children knowledge and learning strategies in subtle ways, but also carry out parent-child communication more effectively (Wu et al., 2017). Third, according to the theory of social reproduction, schools have the attributes of the upper middle class, which makes it difficult for parents from disadvantage families to adapt to the culture and ideology of the school when communicating with teachers or participating in school activities (Sui-Chu \& Willms, 1996; Li \& Zheng, 2017). At the same time, some researchers even found that schools may show discrimination against such parents (Wu et al., 2017). Fourth, specific to immigrant groups, they would also face the obstacles in the aspects of cultural customs, social rules, languages, et al., this would inevitably hinder such parents carry out parent-teacher communication or CP behaviors (Altschul, 2011). As a result, the quantity and quality of parental involvement for LUC, UUMc, RUMC and DMC would be descending.

According to relevant research, the influence of parental involvement behaviors of different socioeconomic groups on children's development cannot be completely determined (Nguon, 2012; Li \& Qiu, 2016). Thus, in current research, whether the effect of parental involvement on academic development would have difference among such four children types is uncertain. If such impact effects are different between among such four children types, targeted guidance information is required for each type of parent to help them better involved in children's education. Since many related studies in the past only focus on some of these types (Zhou \& Wu, 2008; Liu $\&$ Teng, 2016), the conclusions may not be comparable, they cannot provide targeted and effective information for parental involvement in special type of children either. To this end, we attempt to verify hypotheses 1-3 for each type of children group.

\section{Data and Variables}

\section{Data}

Data in this study are collected from the China Education Panel Survey (CEPS) baseline database. In current paper, we do not include all samples of CEPS, but only keep grade 8 (junior) students who study and live in urban areas. Furthermore, to ensure consistency of the sample, this study retains 9727 children with no missing values for all dependent, explanatory and control variables. We define place of residence and household registration in the same province as local, and the household registration in the province as a flow. Combining urban and rural household registration and mobility, the research sample is divided into four groups (number of individuals in group): LUC (4688), RUMC (2973), UUMC (785), and DMC (1231) (the composition ratio is shown in Figure 1). 


\section{Variables}

\section{Academic Development Variables}

Based on the core literacy framework, the academic development variables include two types: 1) test score indicator, specifically, the class scores of children's selfevaluation ${ }^{3}$, and 2) non-test score indicators, including learning willpower, learning curiosity, and self-learning ability and self-education expectations. Among these, learning willpower is based on responses to "even if the body is a little uncomfortable, or there are other reasons to stay at home, I will still try to go to school" and "even if the homework takes a long time to finish, I will continue to do my best." Learning curiosity is measured by reported agreement with the statement "I am very curious about new things." Self-learning ability is measured by response to "I can learn new knowledge quickly." Self-education expectation is highest expected by the students' reported expectations ${ }^{5}$.

\section{Parental Involvement}

Parental involvement is divided into three categories ${ }^{6}$ : DLP, EP, and CP. The aspect of DLP includes four items: 1) how frequently parents check their children's homework; 2) how frequently of parents guide children as they do their homework; 3) parents willingness to participate in parent conferences; and, 4) the frequency of parents' active contact with teachers. The aspect of EP includes two items: 1) the frequency of parents and children discussing school events; and 2) the frequency of parents and children discussing the child's relationship with teachers. The aspect of CP includes four items: 1) frequency of parents and children reading together; 2) frequency of parents and children exercising together; 3 ) frequency of parents and children visiting museums and zoos together; and 4) frequency of parents and children watching a game or performance together. To facilitate interpretation of results, we conduct a factor analysis ${ }^{7}$ for the items in each category and take the first common factor score to synthesize data as indexes for each aspect of parental involvement.

\section{Control Variables}

To reduce estimation bias and identify true effects as much as possible, we introduce control variables from three resources: individual, family and school. Individual level Control variables include gender, grade, cognitive test scores, number of siblings, agricultural household registration, and inter-provincial mobility. Family-level control variables include the parents' maximum number of education years ${ }^{8}$, the family's economic status ${ }^{9}$, and whether the child was living with their parents. School-level control variables include teacher ratios of bachelor, school conditions ${ }^{10}$, and school rankings $(1=$ lower middle, $2=$ upper middle, $3=$ best $)$. 


\section{Description and Comparison of Variables}

To better understand the characteristics of the four categories of children, Table 1 describes the values of different types of children in each variable.

In terms of parental involvement, the parents of LUC scored highest in the three types of participation behaviors, followed by the parents of UUMC parents, and the last two are parents of RUMC and DMC. In terms of children's academic development, LUC score the highest in terms of test score ranking, self-learning ability and self-education expectation, followed by UUMC, and finally two types are also RUMC and DMC. Fortunately, the two types of children who experience rural-urban migrant have shown a slight advantage on the aspects of learning willpower and curiosity. As a result, from the perspective of absolute value comparison, comparing to regional migrant status and such hukou segmentation, rural-urban migrant status and such hukou segmentation show larger negative influence on parental participation behavior and three aspects of children's academic development.

In terms of control variables, there are also some meaningful findings. For example, for the cognitive ability test scores, the scores of LUC, UUMC, RUMC and DMC decrease sequentially, which perfectly mirrors the ranking of the four groups in the test-based academic development score? The rank of cognitive ability test scores is identical with academic test score that means we could solve the "negative choice" problem" - the worse the score, the more parents participate in child's education". In addition, the average values of the parental maximum educational level and family economic status of RUMC and DMC are lower than the other two types of children significantly. Besides, RUMC are far ahead in the indicator of not living with parents compared with other three types of children. This is because the parents of RUMC send their children to local urban areas for further education and RUMC are more likely to choose to stay with relatives, teachers or live at schools due to the similarity of cultural backgrounds and the richness of social relations.

\section{The Influence of Parental Involvement on the Academic Development of Different Types of Children}

Based on the research framework presented above, we take the academic development as the dependent variable and the parental involvement behaviors as the main explanatory variables for constructing a regression model for estimation. Since the data has a nested structure of student within school, this study sets up a two-level model. To test hypotheses 1-3 for each type of children group respectively and compare the heterogeneous effects of different children groups, this study will introduce the interactions among hukou segmentation, migration status and parental involvement behaviors in the model. The benchmark model of this study is:

Level 1: 


$$
\begin{aligned}
\text { xueye }_{\mathrm{ij}}^{\mathrm{s}}=\alpha_{0 \mathrm{j}} & +\sum_{\mathrm{e}=1}^{3} \lambda_{\mathrm{e}} \mathrm{PI}_{\mathrm{ij}}^{\mathrm{e}}+\sum_{\mathrm{e}=1}^{3} \rho_{\mathrm{e}} \mathrm{PI}_{\mathrm{ij}}^{\mathrm{e}} \times \text { rural }+\sum_{\mathrm{e}=1}^{3} \phi_{\mathrm{e}} \mathrm{PI}_{\mathrm{ij}}^{\mathrm{e}} \times \operatorname{migrant}+\sum_{\mathrm{e}=1}^{3} \zeta_{\mathrm{e}} \mathrm{PI}_{\mathrm{ij}}^{\mathrm{e}} \\
& \times \text { rural } \times \text { migrant }+\sum_{\mathrm{k}=1}^{6} \tau_{\mathrm{k}} \text { contr_ind }_{\mathrm{kij}}+\sum_{\tau=1}^{3} \theta_{\tau} \text { contr_fam }_{\tau i j}+\mathrm{e}_{0 \mathrm{ij}}
\end{aligned}
$$

Level 2:

$$
\alpha_{0 j}=\beta_{0}+\sum_{\mathrm{l}=1}^{3} \gamma_{1} \operatorname{contr}_{-} \operatorname{sch}_{\mathrm{lj}}+\mu_{0 j}
$$

Here, equation (1) is the individual-level model, where xueye ${ }^{\mathrm{s}}{ }_{\mathrm{ij}}$ denotes the $\mathrm{s}^{\text {th }}$ academic outcome of interest $(s=1, \ldots, 5)$ for an individual $i$, residing in school $j$ and $\mathrm{PI}_{\mathrm{ij}}^{\mathrm{e}}$ denotes the $\mathrm{e}^{\text {th }}$ parental involvement indicator $(\mathrm{e}=1,2,3)^{11}$. Further, the dummy variables - rural and migrant - reflect hukou segmentation and regional migration status respectively. Besides, contr_ind and contr_fam are individual-level and familylevel control variables, $e_{0 \mathrm{ij}}$ is an individual-level random error term. Equation (2) is the school-level model, where contr_sch are the school-level control variables, and $\mu_{0 \mathrm{j}}$ is the school-level random error term. We will introduce academic development indicators respectively in turn and construct five models. Table 2 presents the results from all aforementioned estimating regressions.

Next, in models 1-5, we calculate the linear combination of which includes the coefficient of parental involvement behavior $\lambda$, the coefficient of the interaction between parental participation behavior and rural $\rho$, the coefficient of the interaction between parental participation behavior and migrant $\phi$, and the coefficient of the interaction among parental participation behavior, rural and migrant $\zeta$. After that, we conduct statistical tests and identify the impact of parental involvement behaviors on academic development of each type of children group in detail (Table 3). What's more, comparing the heterogeneous effects among different types of children is our focus (Table 4). Based on the results presented by Tables 3 and $\mathbf{4}$, we draw the following conclusions:

\section{The Impact of Parental Involvement on Children's Test Score Indicator}

Firstly, parents' DLP has a significant negative impact on the test scores of LUC, RUMC and DMC, which is contrary to Hypothesis 1. Only in UUMC, there is a nonsignificant negative effect, but Hypothesis 1 is still not verified. In terms of intergroup, the negative effects of parents' DLP on the test scores of RUMC and DMC are significantly greater than that of UUMC, and the negative effect of parents' DLP on the test scores of DMC is also significantly greater than that of LUC. In sum, parents' DLP cannot improve the academic test scores of any type of children, and sig- 
Table 1. The Description of Characteristics Based on Hukou and Migration Status Samples.

\begin{tabular}{|c|c|c|c|c|c|c|}
\hline & Dimension & Index & LUC & RUMC & UUMC & DMC \\
\hline \multirow{3}{*}{$\begin{array}{l}\text { Parental } \\
\text { Involvement }\end{array}$} & DLP & $\begin{array}{l}\text { Direct learning participation } \\
\text { behavior index }\end{array}$ & 0.090 & -0.097 & 0.99 & 0.099 \\
\hline & $\mathrm{CP}$ & $\begin{array}{l}\text { Cultural participation behavior } \\
\text { index }\end{array}$ & 0.129 & -0.178 & 0.124 & 0.102 \\
\hline & EP & $\begin{array}{l}\text { Emotional participation behav- } \\
\text { ior index }\end{array}$ & 0.065 & -0.030 & 0.042 & 0.094 \\
\hline \multirow{5}{*}{$\begin{array}{l}\text { Academic } \\
\text { Development }\end{array}$} & $\begin{array}{l}\text { Test score } \\
\text { indicator }\end{array}$ & Last final test class ranking & 3.222 & 2.991 & 3.122 & 3.017 \\
\hline & \multirow{4}{*}{$\begin{array}{l}\text { Non-test } \\
\text { score indi- } \\
\text { cators }\end{array}$} & Learning willpower & 3.340 & 3.406 & 3.274 & 3.339 \\
\hline & & Learning curiosity & 3.515 & 3.542 & 3.478 & 3.498 \\
\hline & & Self-learning ability & 3.117 & 2.965 & 3.019 & 2.942 \\
\hline & & Self-education expectations & 17.36 & 16.49 & 17.03 & 16.17 \\
\hline \multirow{16}{*}{$\begin{array}{l}\text { Control } \\
\text { Variables }\end{array}$} & \multirow{6}{*}{$\begin{array}{l}\text { Individual } \\
\text { Level }\end{array}$} & $\begin{array}{l}\text { Gender ( } 1=\text { Female, } 0= \\
\text { Male ) }\end{array}$ & 0.511 & 0.488 & 0.508 & 0.491 \\
\hline & & $\begin{array}{l}\text { Grade } 9\left(1=9^{\text {th }} \text { grade, } 0=7^{\text {th }}\right. \\
\text { grade })\end{array}$ & 0.482 & 0.487 & 0.375 & 0.389 \\
\hline & & Cognitive ability test score & 0.309 & 0.015 & 0.111 & -0.044 \\
\hline & & Single child $(1=$ Yes, $0=$ No) & 0.741 & 0.349 & 0.536 & 0.269 \\
\hline & & Rural hukou ( $1=$ Yes, $0=$ No) & 0.000 & 1.000 & 0.000 & 1.000 \\
\hline & & $\begin{array}{l}\text { Migration status }(1=\text { Yes, } \\
0=\mathrm{No})\end{array}$ & 0.000 & 0.000 & 1.000 & 1.000 \\
\hline & \multirow{7}{*}{$\begin{array}{l}\text { Family } \\
\text { Level }\end{array}$} & $\begin{array}{l}\text { Father/ mother maximum } \\
\text { education years }\end{array}$ & 12.91 & 9.715 & 12.97 & 9.633 \\
\hline & & Family's financial situation & 2.972 & 2.775 & 2.987 & 2.833 \\
\hline & & Parental living conditions & & & & \\
\hline & & Parents are at home & $82.57 \%$ & $74.10 \%$ & $82.55 \%$ & $86.03 \%$ \\
\hline & & Father is not at home & $8.85 \%$ & $10.12 \%$ & $9.55 \%$ & $4.96 \%$ \\
\hline & & Mother is not at home & $3.20 \%$ & $2.76 \%$ & $3.18 \%$ & $2.52 \%$ \\
\hline & & Parents are not at home & $5.38 \%$ & $13.02 \%$ & $4.71 \%$ & $6.50 \%$ \\
\hline & \multirow{3}{*}{$\begin{array}{l}\text { School } \\
\text { Level }\end{array}$} & School running conditions & 0.710 & 0.679 & 0.725 & 0.705 \\
\hline & & $\begin{array}{l}\text { The ratio of teacher with } \\
\text { bachelor degree or above }\end{array}$ & 0.898 & 0.781 & 0.932 & 0.877 \\
\hline & & School ranking & 2.332 & 2.025 & 2.061 & 1.894 \\
\hline
\end{tabular}

Note: a-The indicator for this dimension is the inter-school level average of the schools where the various groups of children are located 


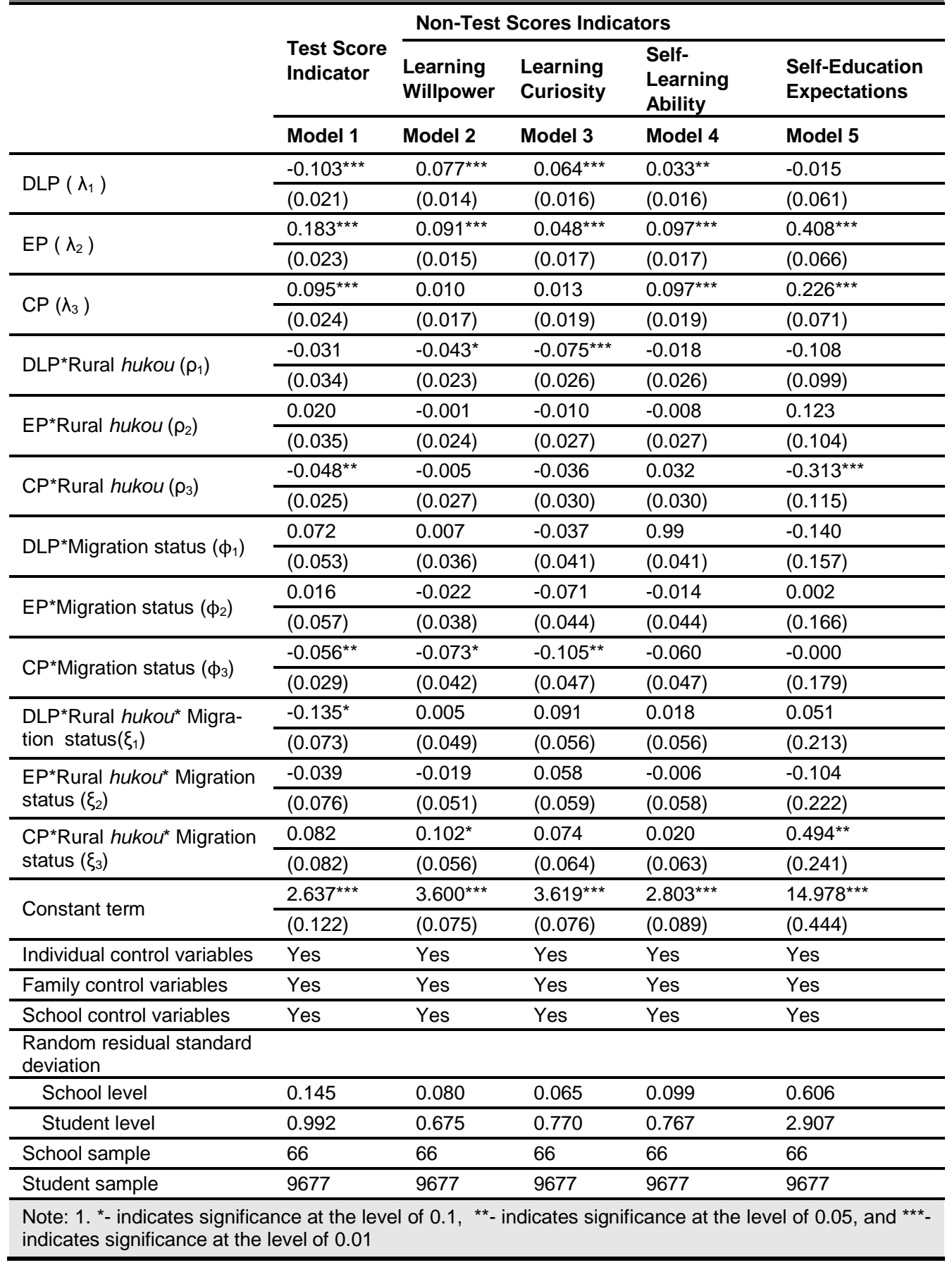


Table 3. The Impact of Parental Involvement on the Academic Development of Four Types of Children Groups.

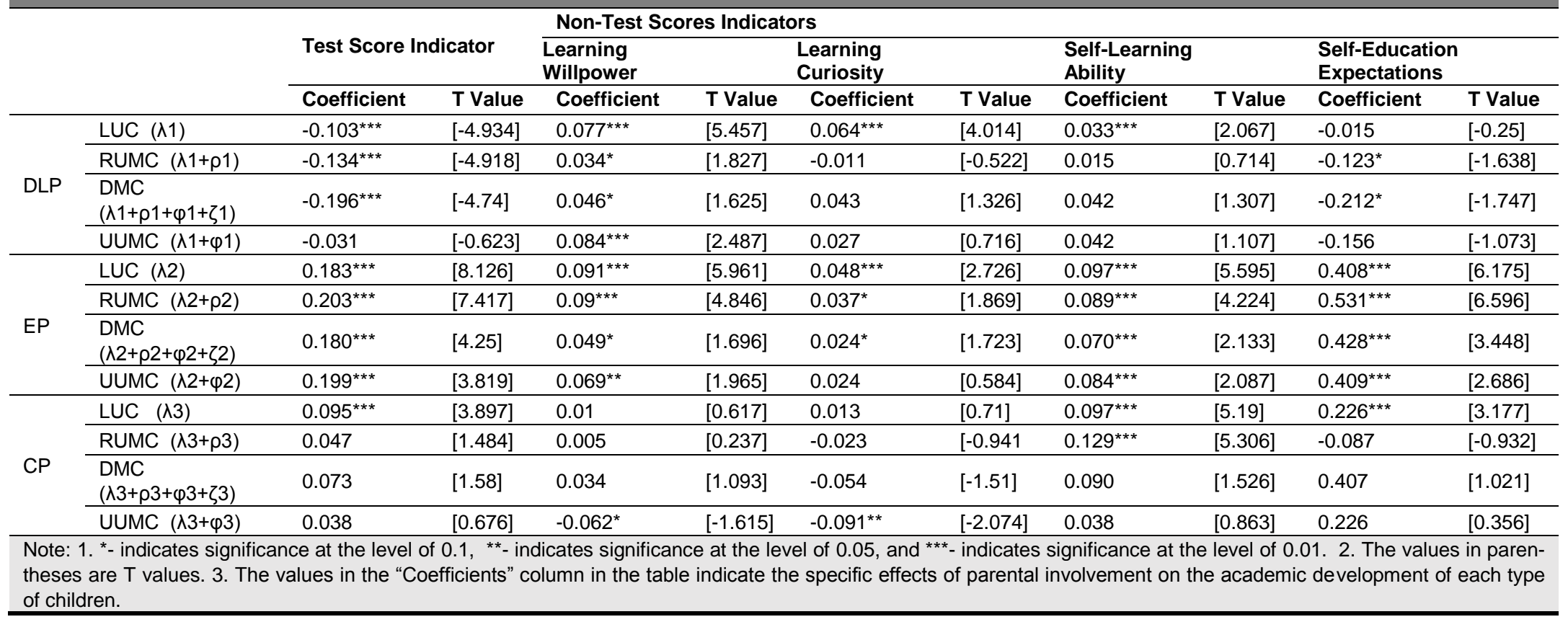


Table 4. Inter-group differences in the influence of parents' participation in the development of four types of children's academ-

ic development.

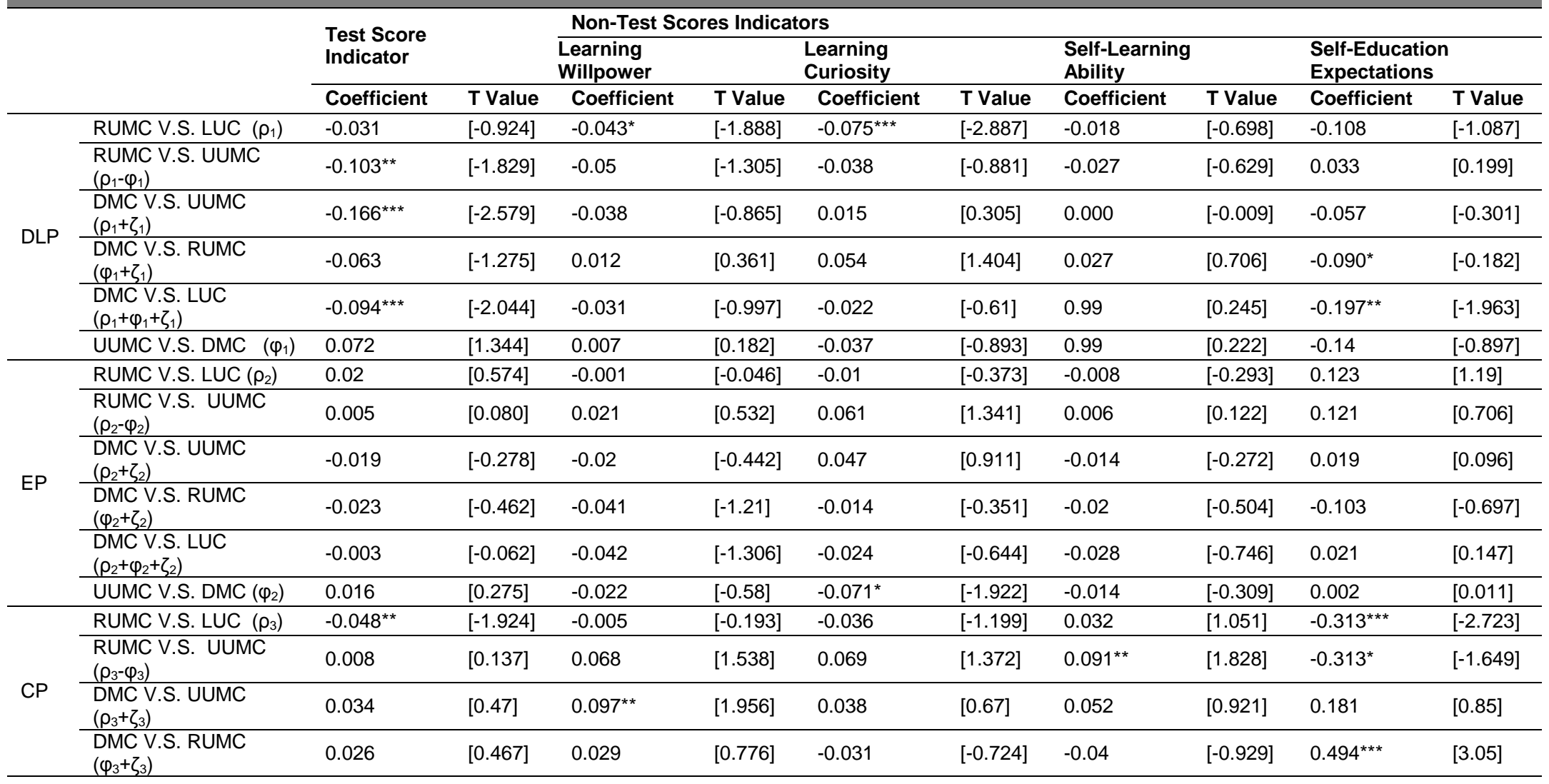




\begin{tabular}{|c|c|c|c|c|c|c|c|c|c|c|}
\hline $\begin{array}{l}\text { DMC V.S. LUC } \\
\left(\rho_{3}+\varphi_{3}+\zeta_{3}\right)\end{array}$ & -0.022 & {$[-0.429]$} & 0.024 & [0.683] & -0.067 & {$[-1.678]$} & -0.008 & {$[-0.196]$} & 0.181 & [1.194] \\
\hline UUMC V.S. DMC $\left(\varphi_{3}\right)$ & $-0.056^{\star \star}$ & {$[-1.919]$} & $-0.073^{*}$ & {$[-1.746]$} & $-0.105^{\star \star}$ & {$[-2.209]$} & -0.06 & {$[-1.259]$} & .000 & {$[-0.002]$} \\
\hline
\end{tabular}


Figure 1. The Composition of Children According to Hukou Segmentation and Migration Status.

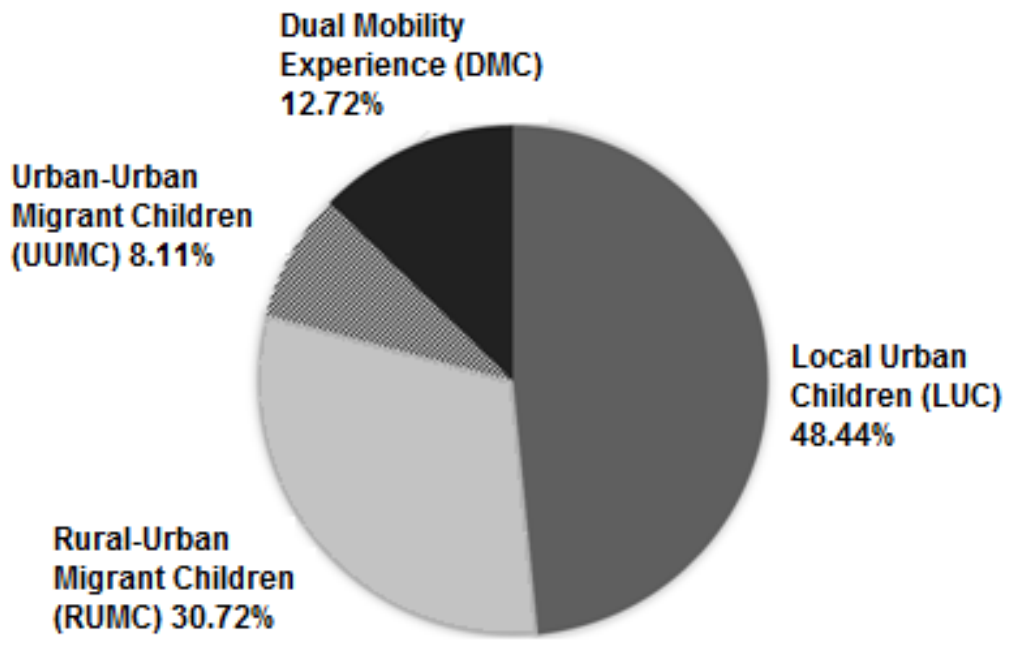

nificantly reduces the academic test scores of all except UUMC. Especially for RUMC and DMC, the negative effects are strongest.

Secondly, parents' EP has a significant positive impact on the test scores of all types of children, which supports Hypothesis 2. No significant differences between groups are observed. This shows that if parents can communicate more with their children about their schools and teachers, academic test scores of all types of children would be improved significantly. What's more, the effects do not differ from each other due to hukou segmentation and migration status.

Finally, parents' CP has a significant positive impact on the test scores of LUC, while the impact is not significant in the other three types of children groups. Therefore, Hypothesis 3 is only verified in LUC. In terms of intergroup, the effects of parents' CP on the test scores of RUMC and UUMC are significantly lower than that of LUC. This means that only LUC can improve their academic test scores through more parents' $\mathrm{CP}$.

\section{The Impact of Parental Involvement on Children's Non-Test Score Indicators}

In this section, we similarly uncover the effects of parental involvement on each nontest score indicator of each type of children from the perspective of parents' DLP, EP and $\mathrm{CP}$.

\section{Learning Willpower}


Firstly, parents' DLP has a significant positive impact on the learning willpower of all types of children, so Hypothesis 1 is supported in each type of children groups. In terms of intergroup, the effect of parents' DLP on the learning willpower of RUMC is significantly lower than that of LUC, but there is no significant difference among the other children groups. Secondly, parents' EP has a significant positive impact on the learning willpower of the four types of children, supporting Hypothesis 2. Pairwise comparisons between groups reveal no significant intergroup differences upon this effect. Finally, parents' $\mathrm{CP}$ has a significant negative impact on the learning willpower of UUMC, which rejects Hypothesis 3. Meanwhile, there are positive but non-significant effects in the other three categories of children and Hypothesis 3 is not verified, either. In terms of intergroup, the influence of parents' CP on the learning willpower of UUMC is significantly different from that of LUC and DMC.

\section{Learning Curiosity}

Firstly, parents' DLP can significantly improve the learning curiosity of LUC, which means Hypothesis 1 is verified in this type of children. In contrary, the effects of parents' DLP on the learning curiosity of RUMC, UUMC and DMC are non-significant and Hypothesis 1 is not supported. In terms of intergroup, the effect of parents' DLP on RUMC's learning curiosity is significantly lower than that of LUC. Secondly, parents' EP can significantly improve the learning curiosity of LUC, RUMC and DMC. Thus Hypothesis 2 is supported in above three types of children groups. But there is positive but non-significant effect in UUMC, reflecting Hypothesis 2 is not testified in UUMC. Focusing on the intergroup, the effect of parents' DLP on UUMC is significantly lower than that of LUC. Finally, parents' CP can significantly impede the learning curiosity of UUMC and Hypothesis 3 is rejected. Meanwhile, the effects of parents' $\mathrm{CP}$ on the other three types of children groups are not significant, and Hypothesis 3 is not supported. Focusing on the results of pairwise comparisons, we can conclude that the impact of parents' CP on UUMC is significantly lower than that of LUC.

\section{Self-Learning Ability}

Firstly, parents' DLP can promote the self-learning ability of LUC significantly, but has a non-significant positive effect on the other three types of children groups, which means Hypothesis 1 is only supported by LUC. Further, no significant differences are observed between groups. Secondly, parents' EP has a significant positive impact on the self-learning ability of all types of children. As a result, Hypothesis 2 is supported in all children samplings. Similarly, there is no significant difference in terms of intergroup. Lastly, parents' CP can significantly improve self-learning ability of LUC and RUMC so that Hypothesis 3 is supported in above two groups. However, the effect of this behavior on the self-learning ability of UUMC and DMC are not significant, of which Hypothesis 3 is not verified. Focusing on the results of 
pairwise comparisons, what draw our attention is that the effect of parents' $\mathrm{CP}$ on RUMC is significantly higher than that of UUMC.

\section{Self-Education Expectations}

Firstly, parents' DLP has a significant negative impact on the self-education expectations for RUMC and DMC, and a non-significant negative impact on the selfeducation expectations for LUC and UUMC. Thus, Hypothesis 1 is rejected in all types of children groups. Among these groups, the negative impact of parents' DLP on DMC is significantly stronger than LUC and RUMC. Secondly, parents' EP can promote the self-education expectations of all four types of children significantly, and Hypothesis 2 is testified completely. What's more, no differences between groups are observed in terms of intergroup. Finally, parents' CP can significantly improve the self-education expectations of LUC, supporting Hypothesis 3. However, in the other three groups, Hypothesis 3 is not accepted. Among these groups, the influence of parents' CP on the self-education expectations of LUC is significantly lower than that of the other three types of children.

\section{Conclusion and Discussion}

The first finding of our study is that parents' DLP has a limited effect on children's academic development. Especially for most academic development indicators of RUMC and DMC, there are significant negative effects. Parents' DLP not only fails to improve the academic test scores and self-education expectations of any type of children, but also has a significant negative impact on the academic test scores and the self-education expectations of LUC, RUMC and DMC. Moreover, the improvement of learning curiosity and self-learning ability occurs only in LUC. In contrast, in terms of learning willpower, improvement occurs in all types of children groups. Focusing on the results of the comparison between groups, the negative impacts of parents' DLP on the academic test scores of RUMC and DMC are significantly stronger than that of LUC and UUMC. Besides, the negative impact of parents' DLP on the self-education expectations of DMC is significantly stronger than that of LUC and RUMC.

We speculate the reason of showing above results is that there is a long-term imbalance between urban and rural education in China, with the conditions for running schools in rural areas lagging behind cities, resulting in agricultural household parents with low level education ${ }^{12}$, poor self-learning strategies, lack of long-term goals, and falling into low social classes. As a result, they not only lack professionalism and effectiveness in guiding and supervising children's learning process, but also may generate frustrating emotions due to classes' segmentation when communicating with teachers (Wu Zhonghan et al., 2017). Hence, Low-quality DLP is likely to convey ineffective learning strategies, repetitive and boring learning content, and resistance to school and learning, which is not conducive to children's academic devel- 
opment (Sui-Chu and Willms, 1996; Zhao Yandong and Hong Yanbi, 2012). It should be noted that while some scholars (Sun, 1998) believe that the "negative selection" problem may lead to overestimating the negative effect of DLP, in this study we introduce the students' cognitive ability score as a control variable to address this problem. At the same time, since the negative selection problem theoretically exists mainly in the estimation of the test score as the dependent variable, the three non-test indicators of self-education expectation, learning curiosity and self-learning ability are consistently estimated, and thus we think that negative selection has little effect on our results and the research results are robust.

The second finding of this study is that parents' EP has a significant role in improving all aspects of academic development for all children groups ${ }^{13}$, and there is no significant difference in terms of hukou segmentation and migration status. This finding is consistent with existing literature (Sui-Chu and Willms, 1996; Jr. McNeal, 1999; Zhao Yandong and Hong Yanbi, 2012; Huang Shuang and Huo Liyan, 2014). We believe that this result is due to the fact that through communicating with their children more about learning, schools, and teachers, parents can build a closer relationship and trust with their children, and form social closure with their children, the classmates of children, teachers, school and the parents of their children's classmates, which not only enables children to feel the great attention that parents pay to their learning, but also reduces the information asymmetry of parents on children's learning process. Accordingly, parents' EP is a great social capital that can encourage and promote the development of children's academic development. Meanwhile, communicating with their children is relatively less constrained by the parents' own literacy; therefore, parents' EP can enhance academic development in different types of children groups.

The third finding of this study is that the positive impact of parents' CP is mainly reflected in LUC. This effect is not significant or even negative in rural hukou and non-local children's groups and, in particular, there is a significant negative effect on learning curiosity and learning willpower in DMC, indicating that the regional division restricts the beneficial effect of parents' $\mathrm{CP}$ on the development of non-local children's academic development. We speculate the reason is that there are cultural, social, and psychological integration problems for the migrant children. Specifically, due to the differences on cultural and social aspects between the growing surroundings and the local region, migrant children's parents tend to have some difficulties in choosing suitable urban cultural resources. Moreover, migrant children may not be able to resonate and gain benefits when they participate in relevant recreational activities, conversely, they are more likely to feel bored or discriminated against in their activities, which may restrict the positive effects of parents' PE eventually.

In summary, the findings of this study provide some guidelines when parents participate in their children's education. First, in the process of teaching students, the school cannot extend the responsibility of direct learning intervention, such as guidance and counseling knowledge, to students' parents; knowledge conveying should remain teacher-led. Due to the lack of professionalism, parents' DLP not only nega- 
Liang et al. Parental Involvement and Children's Academic Development

tively affect multiple academic development indicators of the socioeconomic disadvantaged rural hukou children groups, but also plays a limited role in the academic development of relatively high cultural level children groups. Second, schools should encourage parents to communicate more with their children about learning and school at home. The social capital built by parents through this kind of emotional participation behavior is the key to make up for the weaknesses of class teaching system and collective education, which can effectively strengthen positive emotions and weaken negative emotions of children, thereby helping children to achieve comprehensive academic development. Further, above effectiveness will not change due to the difference in hukou and migration status. Third, under the background of accelerating urbanization, the regional differences of cultural systems cause problems of educational integration for migrant children. Thus, schools should make good use of modern media such as the Internet platforms to provide the parents of rural hukou and migrant children with more appropriate recreational activities-related information.

In the future, we can consider to improving the study based on the following aspects. First, this paper discussed children's academic development under the framework of key competences comprehensively and systematically, but the indicators used were children's self-reported data. Hence, the measurement tools need to be modified further. Second, although this paper introduced students' cognitive ability test scores to solve the endogenous problems such as "negative selection", it was still difficult to ensure that we obtained the causal effect of parents' involvement on children's academic development. Therefore, relevant researches need to be improved based on quasi-experimental design and other means. Third, based on the hukou and migration status, we divided all the children into four types and uncovered, compared the effect of parental involvement on the academic development of four types of children respectively, thereby offering parents targeted suggestions. However, due to the change of migration status and migration periods, the relationship between parental involvement and children's academic development may be change correspondingly, so relevant researches need to analyze based on longitudinal data.

\section{Notes}

1 The most important and distinctive part of the "Head start" program is to help parents better get involved in their children's learning and life, for example, "providing parents with the trainings about home literacy skills and parenting skills in order to develop their skills to communicate with their children. See: http://www.nhsa.org/.

2 The "Success for All" program aims to interfere with the learning of students from disadvantaged families by guiding family support effectively, for example, "the program requires parents to accompany their students to read at home for 20 minutes every night, and teachers to provide appropriate guidance for parents." See: http:// www.successforall.org/.

3 Since there is no uniform academic standardized test in the existing large public databases, it is feasible to use the student self-reported score ranking as a test score indica- 
Liang et al. Parental Involvement and Children's Academic Development

tor. Although above act may be affect the accuracy and comparability of the measurement, considering that the study focuses on estimating the directionality of the impact (positive or negative), we think it is a compromise.

4 The items of learning willpower, learning curiosity and self-learning ability are all ordered variables of 1-4. The higher the value, the better the academic development of the corresponding dimensions.

5 The assignment rules of self-education expectations: "Quit now" = 6 years (seventh grade) or 8 years (ninth grade); "Middle school graduation" = 9 years; "Secondary school/Technical school" or "Vocational High School" = 11 years; "High school" = 12 years; "College" = 15 years; "Four-year bachelor" = 16 years; "Graduate" = 19 years; "Doctor" = 22 years.

6 In terms of parental involvement, except for "Whether the parents are willing to show up the parent meeting" (dummy variable, $1=$ Yes, $0=$ No), all the other variables are 1 4 ordered variables, and the higher the value, the higher the frequency of the corresponding behavior.

7 In the three types of parental involvement, the variance contribution rate of the first common factor is more than $90 \%$, indicating that it can represent most of the information in the items included in each parental involvement dimension.

8 "No education" = 0 year; "Primary school" = 6 years; "Middle high school" = 9 years; "Secondary school/Technical school" and "Vocational High School" = 11 years; "High school" = 12 years; "College" = 15 years; "Four-year bachelor" = 16 years; "Graduate and above" = 19 years.

9 The assignment rules of family economic conditions: $1=$ Poor, $2=$ Middle, $3=$ Wealthy.

10 In the school questionnaire, 10 questions such as "Is there a laboratory", "Is there a swimming pool" $(1=$ Yes, $O=N o)$ are weighted and summed according to the reciprocal of the proportion, and then standardized.

11 Strictly speaking, an ordered logit model should be constructed, but this is not convenient for interpreting the interaction term coefficients. To this end, we construct a common two-level regression model with each academic development variable as a continuous variable, although the size of coefficients is biased, considering the main focus of the study, the directionality of coefficients will not be influenced.

12 In fact, combined with the data in Table 1 and the existing literature (Xie Guihua, 2012; Ma Xiaohong, 2014), the cultural quality of rural hukou parents is significantly lower than that of urban hukou parents, while the cultural quality of local parents are lower than non-local parents in terms of migration status.

13 The positive impact of learning curiosity is not significant only for UUMC. 


\section{References}

Altschul, I. (2011) Parental involvement and the academic achievement of Mexican American youths: what kinds of involvement in youths' education matter most. Social Work Research; 35(3): 159-170.

Altschul, I. (2012) Linking Socioeconomic status to the academic achievement of Mexican American youth through parent involvement in education. Journal of the Society for Social Work and Research; 3(1): 13-30.

Brooks, N., Bruno, E., \& Burns, T. (1997) Reinforcing students' motivation through parent interaction. Elementary School Curriculum; 12(1): 109 .

Currie, J. M. (1997) Choosing among alternative programs for poor children. The Future of Children; 7(2): 113-131.

Chu Hongqi. (2016) The international vision of core literacy and China's stand -- China's national quality improvement and educational goal transformation in the 21 st century. Educational Research; 37(11): 8-18.

Fan, W., \& Williams, C. M. (2010) The effects of parental involvement on students' academic self - efficacy, engagement and intrinsic motivation. Educational Psychology; 30(1): $53-74$.

Fan, X., \& Chen, M. (2001) Parental involvement and students' academic achievement: a meta-analysis. Educational Psychology Review; 13(1): $1-22$.

Feng, S.Z, \& Chen, Y.Y. (2016) The future of the city -- Shanghai model of migrant children's education. Shanghai University of Finance and Economics Press.

Gonzalez, A. R., Doan Holbein, M. F., \& Quilter, S. (2002) High school students' goal orientations and their relationship to perceived parenting styles. Contemporary Educational Psychology; 27(3): 450-470.

Grolnick, W. S., \& Slowiaczek, M. L. (1994) Parents' involvement in children's schooling: a multidimensional conceptualization and motivational model. Child Development; 65(1): $237-252$.

He, A.X., \& Li, R.M. (2000) The status, function and cultivation of emotion in learning to learn. Journal of the Chinese Society of Education; 4:38-40.

Hanushek, E. A., \& Woessmann, L. (2008) The role of cognitive skills in economic development. Journal of Economic Literature; 46(3): $607-668$.
Heckman, J. J., Stixrud, J., \& Urzua, S. (2006) The effects of cognitive and noncognitive abilities on labor market outcomes and social behavior. Journal of Labor Economics; 24(3): $411-482$.

Hill, N. E., \& Tyson, D. F. (2009) Parental involvement in middle school: a meta-analytic assessment of the strategies that promote achievement. Developmental Psychology; 45(3): $740-763$.

Huang, S., \& Huo, L.Y. (2014) The main influencing factors of children's learning quality: foreign research progress and its enlightenment. Comparative Education Review; 36(5):40-45.

Jr. McNeal, R. B. (1999) Parental involvement as social capital: differential effectiveness on science achievement, truancy, and dropping Out. Social Forces; 78(1): 117-144.

Li, J.L. (2017) Influence of parental involvement and intergenerational closure on cognitive ability of junior high school students -based on Coleman's social capital theory. Research in Educational Development; 37(Z2):6-14.

Li, X.H., \& Zheng, L. (2016) Does social capital work? Generation closure and children's academic performance in rural families. Journal of Educational Studies; 12(3):45-53.

Li, X.H., \& Zheng, L. (2017) The influence of family socioeconomic status on parental involvement and its mechanism -- based on CEPS data. China Economics of Education Review; 2(1):86-104.

Li, Z.L., \& Qiu, Z.Q. (2016) How does family background affect children's academic achievement? -- analysis on the influence of family socioeconomic status on compulsory education. Sociological Studies; 4:121-144.

Liu, G.R., \& Teng, X.Q. (2016) The influence of parental involvement on the academic performance of migrant children: the mediating effect of autonomous motivation. Psychological Exploration; 36(5):433-438.

Nguon, S. (2012) Parental involvement and students' achievement in Cambodia: focusing on parental resourcing of public schooling. International Journal of Educational Research; 53:213-224.

Patall, E. A., Cooper, H. \& Robinson, J. C. (2008) Parent involvement in homework: a research synthesis. Review of Educational Research; 78(4): 1039-1101.

Plunkett, S. W., Henry, C. S., Houltberg, B. J., Sands, T., \& Abarcamortensen, S. (2008) 
Academic support by significant others and educational resilience in Mexican-origin ninth grade students from intact families. Journal of Early Adolescence; 28(3): 333355.

Qiao, N., Zhang, J.H., Liu, G.R. \& Lin, C.D. (2013) Effects of family socioeconomic status and parental involvement on the academic performance of junior high school students: moderating effects of teacher support. Psychological Development and Education; 29(5):507-514.

Sui-Chu, E. H., \& Willms, J. D. (1996) Effects of parental involvement on eighth-grade achievement. Sociology of Education; 69(2): 126-141.

Sun, Y. (1998) The academic success of EastAsian-American students-an investment model. Social Science Research; 27(4): 432 -456 .

Shao, J.J., Li, D., Guo, F., Wu P.P., \& Zhang, D.J. (2016) Parental education involvement and migrant children's academic performance, emotional adaptation: mediating role of sense of autonomy and ability. Chinese Journal of Special Education; 1:48-55.

Sibley, E., \& Dearing, E. (2014) Family educational involvement and child achievement in early elementary school for American-Born and immigrant families. Psychology in the Schools; 51(8): 814-831.

Wang, M. T., \& Sheikh-Khalil, S. (2014) Does parental involvement matter for student achievement and mental health in high school? Child Development; 85(2): 610625.

Wilder, S. (2014) Effects of parental involvement on academic achievement: a metasynthesis. Educational Review; 66(3): 377397.

Wu, Z.H., Zhang, J., \& Wang, M.W. (2017) What hinders parents' involvement in their children's education -- class differences, selective inhibition of school and parental involvement. Educational Research; 38(1):8594.

Xie, G.H. (2012) The return of human capital of China's floating population and social integration. Social Science in China; 4:103-124.

Yang, Z.C. (2017) Probing into the essence and practice of core literacy. Educational Research; 38(7):14-20.

Zhao, Y.D., \& Hong, Y.B. (2012) Access to social capital and education -- a perspective of network resources and social closure. Sociological Studies; 5:47-68.

Zhou, H., \& Wu, X.W. (2008) Educational performance of migrant children and its influencing factors: multi-level linear model analysis. Population Research; 32(4):22-32.

Received: 20 February 2019

Revised: 07 March 2019

Accepted: 19 March 2019

The Chinese version of this article has been published in China Economics of Education Review 2018; 3(3):40-60. The English version has been authorized for being publication in BECE by the author(s) and the Chinese journal.

梁文艳, 孙丹, 叶晓梅. 核心素养视角下父母参与如何影响儿童的学业发展? 基于城乡户籍 和区域流动状况的差异分析. 教育经济评论 2018; 3(3):40-60. 